\title{
Development of a test bench assessing the hydrodynamic compliance of vascular prostheses
}

\begin{abstract}
For more than sixty years, textile vascular grafts have saved millions human lives, but achieving attributes of a native artery still remains a challenge, especially in terms of parietal distensibility, commonly called compliance, necessary to transform intermittent blood ejection into steady and continuous flows. The graft compliance is, in part, related to the fabric contexture and the kind of yarns used in relation with the prosthetic finishing treatments. The objective of the present paper was to evaluate the mechanical behavior of prosthetic fabrics, made with various polyester multifilament yarns, subjected to fatigue stresses under realistic test conditions performed in vitro. For this purpose, cyclic tests have been applied to prosthetic tubes by using both mechanical testing machine and test bench specially developed for simulating the mechanical aging induced by water pressure on the prosthetic wall. This instrument allows the injection of pulsatile water adjustable in frequency and pressure in vascular grafts previously sealed by a rubber bladder while simultaneously monitoring the prosthesis wall distention by a high resolution displacement transducer linked to data acquisition software. Compliance curves thus made it possible to identify the highdistensibility prosthetic structures whose cyclic dilation could be maintained almost stable throughout the fatigue tests.
\end{abstract}

Keywords: vascular graft, test bench, prosthesis dilation, compliance, in vitro test
Volume 4 Issue 3 - 2018

\author{
Helmi Khlif,' Soufien Dhouib,' Najeh \\ Maâtoug,' Saber Ben Abdessalem,' Faouzi \\ Sakli' \\ 'Textile Engineering Laboratory, University of Monastir, Ksar \\ Hellal,Tunisia \\ ${ }^{2}$ Textile Materials and Processes Research Unit, University of \\ Monastir, Monastir, Tunisia
}

Correspondence: Helmi Khlif, Textile Engineering Laboratory, University of Monastir, Avenue Hadj Ali Soua, 5070 Ksar Hellal, Tunisia, Tel 0021621446565, Email helmi.khlif@yahoo.fr

Received: May 14, 2018 | Published: June II, 2018

\section{Introduction}

The complications related to synthetic fibre fabrics used as vascular grafts are not uncommon. Dilation, aneurysmal failure, structural defects, interstitial bleeding and infection are among the most reported complications affecting medium and large caliber (more than $8 \mathrm{~mm}$ diameter) polyethylene terephthalate (PET) prostheses. ${ }^{1-5}$

The dilation, the most cited complication, is characterized by a remnant expansion of the prosthesis diameter under the cumulative effect of blood pressure. Due to the mechanical mismatch between graft and host artery, early dilation generally occurs during the few weeks following implantation: circumferential expansions close to $10 \%$ for woven prostheses and $20 \%$ for knitted ones have been thus recorded. ${ }^{6-9}$ Compliance mismatch particularly contributes to induce aneurysms, anastomotic rupture and sub-intimal hyperplasia, which makes the graft ineffective and seriously threatens the patient life. ${ }^{10-12}$ Dilation beyond 1 month of implantation is usually slower for both knitted and woven grafts. ${ }^{13,14}$ Some studies mentioned dilation rates rising from $12 \%$ at 1 month to $15 \%$ at 2 years and from $6 \%$ at 2 weeks to $8 \%$ at 1 year for woven grafts. ${ }^{15}$ The knitted ones, on the other hand, dilate more, for example from $28 \%$ at 1 month to $34 \%$ at 2 years ${ }^{15}$ and from $19 \%$ at 2 weeks to $31 \%$ at 2 years, ${ }^{8}$ though most of the dilation arose in precocious way. However, the dilation evolution at very long term remains rarely reported (from $6 \%$ at 5 years to $30 \%$ at 8 years and from $60 \%$ at 10 years to $70 \%$ at 15 years). ${ }^{16,17}$

Mechanical fibre fracture in vivo, fibre alteration during manufacturing or surgical manipulation and repeated or inappropriate sterilization processes have been highlighted as the main causes of prosthetic dilation. ${ }^{18-20}$ Although PET is recognized as biologically stable, biodegradation could occur over time due to the degenerative effect of both tissue fluids and enzymes. ${ }^{21}$ Data on fatigue and other appropriate graft properties that might explain the dilation phenomenon are either unavailable or the information is inconclusive. Therefore, the present paper aims to evaluate the mechanical behavior of prosthetic tubes subjected to fatigue stresses under realistic test conditions performed in vitro. For this purpose, cyclic tests have been applied to woven specimens by using both mechanical testing machine and test bench specially developed for simulating systolic and diastolic blood pressures.

\section{Materials and methods}

\section{Materials}

The materials tested were three contextures (C1-C3) of vascular grafts made from different types of PET multifilament yarns (Table 1). These fabrics have been compact woven as seamless tubes on a narrowfabric needle loom NFJM2 (Jakob Müller). In such plain-weave patterns, warp yarns lie alternately over and under weft ones thus conferring maximum interlacing points on fabric and therefore best mechanical performances among all types of weaves. ${ }^{22,23}$ To improve both resistance to radial compression and kinking, the prosthetic tubes have been crimped by using the cord-winding technique minutely described in previous works. ${ }^{18,24}$ The accordion pleats have been fixed on the prosthetic wall by steaming it at $170^{\circ} \mathrm{C}$ for 1 hour. After being finished using the same procedure, all samples had the same diameter and crimp geometry (width and depth).

\section{Fatigue testing}

The current standards texts, established by European or international commissions, concerning the mechanical performances of vascular prostheses are not precise enough to avoid inaccuracy related to test procedures and difference of interpretation. ${ }^{25,26}$ Consequently, the result of tests may present different values depending on the laboratory where they are performed. Moreover, these standards 
essentially focus on characterizing the specimen breaking stresses whether they are unidirectional (longitudinal or transversal tensile tests) or multidirectional (burst test) without taking into account the behavior in deformation or the aptitude to dilate. ${ }^{26,27}$ By introducing mechanical fatigue to prosthetic walls, cyclic loading tests take into account the time factor and allow giving a realistic evaluation of the prosthetic compliance.

Compliance (C) is defined as the function of damping, by an artery or arterial graft, the pulsatile flow generated by the intermittent cardiac blood ejection. Compliance is an intrinsic property of the arterial conduit. It characterizes the distensibility of the arterial conduit, generally reported for the physiological pressure range, and is calculated according to the following equation ${ }^{10,28}$ :

$$
\mathrm{C}=\frac{\Delta \mathrm{V} / \mathrm{V}}{\Delta \mathrm{P}}
$$

Where $\Delta \mathrm{V}$ is the change of volume in the arterial conduit, $\mathrm{V}$ the conduit volume and $\Delta \mathrm{P}$ the change of liquid pressure inside the conduit.

Compliance is therefore equal to strain divided by $\operatorname{stress}^{29}$ and is commonly measured through the use of the dynamic ratio, which describes the incremental increase in conduit volume per unit pressure change during the pulse cycle. Alternatively, when the conduit length is kept almost stable (when the graft ends are fixed), the measurement may address the change in diameter through the ratio ${ }^{10,30,31}$ :

$$
\mathrm{C}=\frac{\Delta \mathrm{D} / \mathrm{D}}{\Delta \mathrm{P}}
$$

Where $\Delta \mathrm{D}$ is the change of the conduit diameter and $D$ the inner diameter of the conduit.

\begin{tabular}{|c|c|c|c|}
\hline Fabric contexture & Cl & $\mathbf{C 2}$ & C3 \\
\hline Warp yarns & \multicolumn{3}{|c|}{ Intermingled Diolen $6 \mathrm{IST} \circledast, 280 / 48 / 130^{\mathrm{a}}$} \\
\hline Weft yarns & $\begin{array}{l}\text { Textured } \\
\text { Dacron } \circledast 167 / 68 / 0^{*}\end{array}$ & $\begin{array}{l}\text { Intermingled Diolen } \\
57 T \circledast / 40 / 24 / 20^{*}\end{array}$ & Low-twistedViscosuisse $® / 45 / 30 / 100 *$ \\
\hline Warp count (ends/cm) & 29.1 & 29.1 & 29.1 \\
\hline Weft count (picks/cm) & 29.1 & 34.2 & 34.2 \\
\hline Area density $\left(\mathrm{g} / \mathrm{m}^{2}\right)$ & 177 & 174.2 & 180.7 \\
\hline Thickness (mm) & 0.27 & 0.27 & 0.26 \\
\hline Porosity (\%) & 53.1 & 53.5 & 49.3 \\
\hline Inner tube diameter $(\mathrm{mm})$ & 18 & & \\
\hline
\end{tabular}

Table I Characteristics of prosthetic specimens

aFibre spinning mills specifications: yarn count (dtex) / no. of filaments / twist per meter

\section{Cyclic circumferential tensile test}

Although the circumferential tensile test conducted to rupture provides a quick and simple method for prosthesis characterization, it does not give clear information as to the susceptibility of the prosthetic tube to dilation ${ }^{25,26}$ since the in vivo stresses are relatively low but repetitive. It would then be more interesting ${ }^{10,26}$ to consider fatigue tests applied by a series of cyclic circumferential tensile stresses on prosthetic tubes to follow their diameter changes thus revealing possible embrittlement due to the "mechanical aging" of textile structures.

A tubular specimen is placed around two hemi cylindrical rods firmly held in grips to avoid vibration during cyclic testing (Figure 1). To simulate the pulsatile cardiac regime, cyclic tensile stresses varying between two limiting forces: $\mathrm{F}_{\min }$ and $\mathrm{F}_{\max }$ are applied to the prosthetic tube specimens. As usually carried out in textile fatigue tests, $\mathrm{F}_{\max }$ was chosen as half the average breaking force obtained in preliminary circumferential tensile tests applied to $\mathrm{C} 1-\mathrm{C} 3$ contextures. However, a ratio $\mathrm{F}_{\min } / \mathrm{F}_{\max }$ was set at $2 / 3$ as in physiological conditions.

For each fabric structure, 10 specimens were submitted to cyclic circumferential test. This was performed on a constant elongation gradient dynamometer (Lloyd Instruments LRX $2.5 \mathrm{kN}$ ) according to the procedure listed in Table 2, inspired by ANSI/AAMI/ISO7198: 1998/2001 standard..$^{32,33}$

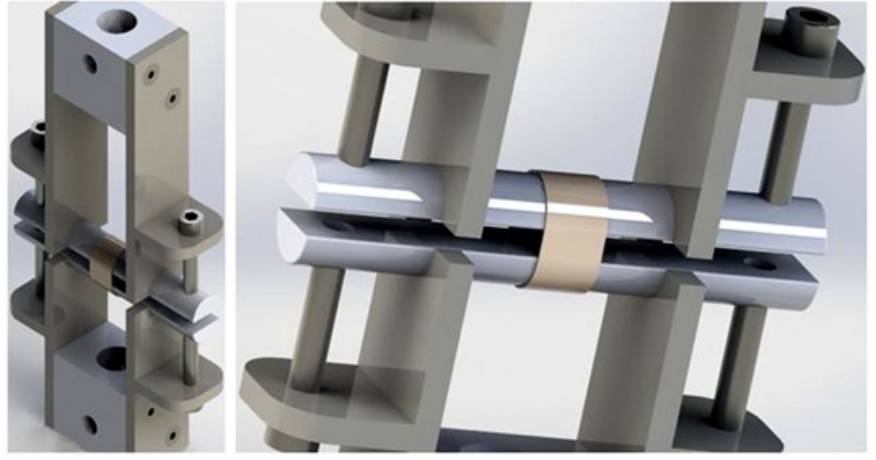

Figure I Schematic of circumferential tensile grips developed for prosthetic tubes testing.

\section{Hydrodynamic compliance test bench}

Overview: To ensure realistic in vitro fatigue conditions, a hydrodynamic stimulation bench has been developed. It subjects the arterial prostheses to preset pulsatile hydraulic flows adjustable in frequency and pressure, which inflict accelerated aging on these structures. The prosthetic distensibility evolution is therefore simultaneously monitored. 
Table 2 Cyclic circumferential tensile test procedure

\begin{tabular}{ll}
\hline Total number of cycles & $\mathbf{5 , 0 0 0}$ \\
\hline $\begin{array}{l}\text { Cycle time (obtained by } 300 \mathrm{~mm} / \mathrm{min} \\
\text { upper grip movement speed) }\end{array}$ & $0.8 \mathrm{~s}$ \\
Initial usable length & $12 \mathrm{~mm}^{\mathrm{b}}$ \\
Limit forces: $\mathrm{F}_{\min }-\mathrm{F}_{\max }$ & $40-60 \mathrm{~N}(800-1200 \mathrm{mmHg})$ \\
Pretension & $3 \mathrm{~N}$ \\
\hline
\end{tabular}

${ }^{a}$ measured, before starting test, on flattened prosthetic wall (after crimping elimination)..$^{33}$

brecommended value for prosthesis radial tensile testing according to AAMI/ ISO 7198: 2016.

During last decades, some instruments generating pneumatic ${ }^{10}$ or hydraulic ${ }^{34}$ flows have been proposed to develop protocols that could predict material behavior and reveal which grafts potentially induce complications associated with dilation. Using hydraulic pumps ${ }^{35}$ or pistons driven by camshafts, ${ }^{36}$ these instruments evaluate the static or dynamic graft compliance, but generally offer limited setting range in terms of frequency and pressure. To reduce testing time and therefore costs, some graft test benches make use of overly exaggerated constraints (dynamic forces up to $200-400 \mathrm{~N}$ ) and seem rather suitable for stent fatigue characterization. Ultra high pulsatile frequencies (up to $120 \mathrm{~Hz}$ ) are also employed, giving the textile structures too little time to recover. ${ }^{37}$

\section{Equipment}

The test bench that we developed (Figure 2) consists of two main parts: a device for generating pulsatile hydraulic flow through a rubber tube inserted in the prosthetic sample and a measuring chain that records and displays real time distention of the prosthetic wall.

The first device (Figure 3) comprises a hydraulic pump, a solenoid valve, a water tank and a set of piping (hoses, valves, gaskets, etc.).

Controlled by a pressure regulator, a hydraulic pump fed by a water tank via a suction strainer, injects water in closed loop through a rubber tube tightly introduced inside a prosthetic specimen. A suitable fastening of the nuts holding its ends permits to preclude any longitudinal displacement. A plastic container seals the device in case of water leakage that may occur, for example, by accidental tearing of the rubber tube.

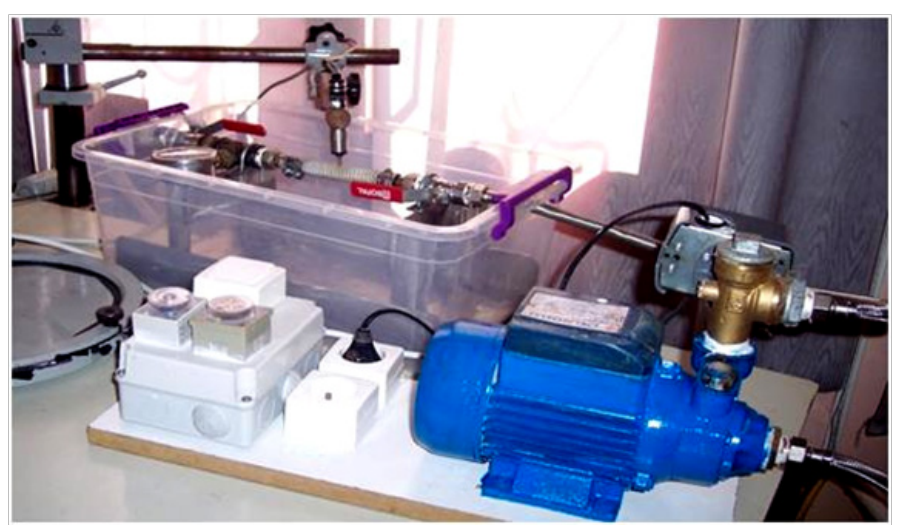

Figure 2 Overview of the developed test bench.
A solenoid valve actuated by two alternatively acting timers produces pulsatile cycles at two preset frequencies. The test is started by plugging the pump and opening both the needle valves. With the timers set to zero, creep tests could be performed: the pump then generates a continuous water flow inside the tubes; once the desired pressure is reached, the exhaust needle-valve would be kept closed and the pump deactivated. Controlled by the pressure regulator, the pump is triggered automatically each time the pressure drops due to creep of the prosthetic wall.

The radial extension of the prosthetic tubes was monitored by using the patented TST measuring chain ${ }^{38}$ originally dedicated to evaluate the surface roughness parameters of textile fabrics. ${ }^{39}$ At the test beginning, an inductive sensor with mobile magnetic core is put in contact with the midpoint of the specimen wall upper boundary (Figure 4) and the pulsatile inflation of the conduit animates the sensor feeler in vertical vibrations. The designed feeler was in the form of a $12 \mathrm{~mm}$ diameter disk suitable for all kinds of prosthetic surfaces, particularly crimped ones.

The feeler displacements are converted into an electric signal which is measured in real time, digitized and stored by using data acquisition software (Bench Link Data Logger 3). The latter likewise allows setting the acquisition parameters, mainly the sampling time, the number of samples, as well as the type of signal to be measured (voltage or intensity). Correlation equations $\left(\mathrm{R}^{2} \approx 1\right)$ make it possible to transform the variations of the voltage delivered $(\mathrm{V})$ by the sensor into amplitude variations $(\mathrm{mm})$ resulting from the radial expansion of the prosthetic wall.

Procedure: After calibration of the measuring chain, each sample of crimped prosthetic tubes was mounted on the test bench with a tension allowing flattening its wall (eliminate the wavy configuration). The two clamping grids that maintain the prosthetic specimen were $18 \mathrm{~cm}$ apart (10 times the inner prosthetic diameter). The sample was then subjected to a fatigue test under the conditions of Table 3, which suggest super physiological constraints causing accelerated aging of the prosthetic tube (stresses are 17 times greater than the physiological ones).

Five specimens of each fabric contexture (C1-C3) were tested. For each specimen, 50,000 measurements (also called scans) of electrical voltage delivered by the sensor were recorded and converted in $\mathrm{mm}$ of the feeler displacement (height h, Figure 5). The rubber tube acting as sealing bladder of the textile prosthesis was exchanged with each new test.

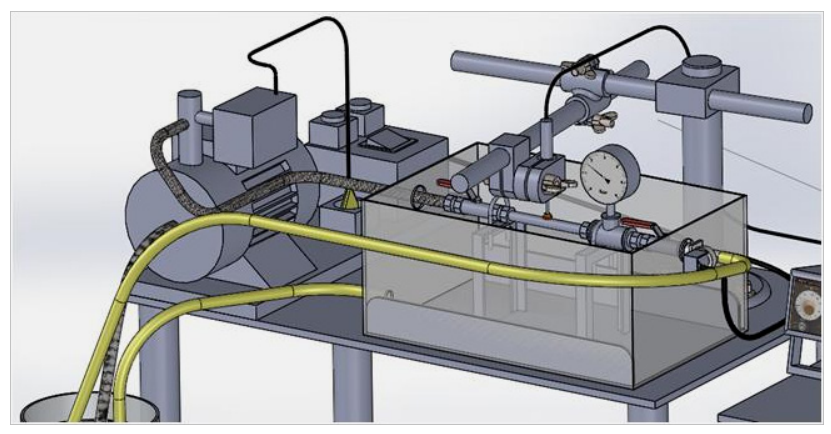

Figure 3 Schematic of the device developed to generate pulsatile hydraulic flows through prosthetic conduits.

I:Timers (0-5s), 2: Pressure regulator (0-4bar), 3: Hydraulic pump, 4: Water tank (5L), 5: Timer control circuit, 6: Transducer, 7: Supply needle-valve, 8: Exhaust needle-valve, 9: Glycerin manometer, 10:Solenoid valve, I I:Prosthetic specimen wrapping a rubber tube, 12: Sealing container, 13: Overflow pipe 
Table 3 Test bench settings used for experimental procedure

\begin{tabular}{|c|c|c|c|}
\hline \multicolumn{4}{|l|}{ Flow setting } \\
\hline \multirow[t]{2}{*}{ Parameters } & Normal physiological conditions ${ }^{40}$ & Set conditions & \multirow[t]{2}{*}{ Setting items } \\
\hline & Systole pressure $=120 \mathrm{mmHg}$ & Maximum pressure $=2.7 \mathrm{bar}(\sim 2020 \mathrm{mmHg})$ & \\
\hline \multirow[t]{2}{*}{ Pulsatile flow } & Diastole pressure $=80 \mathrm{mmHg}$ & Minimum pressure $=1.8 \mathrm{bar}(\sim 1350 \mathrm{mmHg})$ & \multirow[t]{2}{*}{ Pressure regulator } \\
\hline & Pressure ratio (diastole/systole) $=2 / 3$ & Pressure ratio $(\min / \max )=2 / 3$ & \\
\hline Pulsatile rate & 60-100heartbeat/s & 80 beat $/ \mathrm{min}(0.75 \mathrm{~s} / \mathrm{cycle})$ & Timers \\
\hline \multicolumn{4}{|c|}{ Data acquisition setting } \\
\hline \multirow{5}{*}{$\begin{array}{l}\text { Data acquisition } \\
\text { parameters }\end{array}$} & \multicolumn{2}{|l|}{ Sensor supply voltage $=3 \mathrm{~V}$} & Power supply unit \\
\hline & \multicolumn{2}{|c|}{ Type of measured signal: voltage (proportional to feeler displacement) } & \multirow{4}{*}{$\begin{array}{l}\text { Data acquisition contro } \\
\text { unit }\end{array}$} \\
\hline & \multicolumn{2}{|c|}{ Sampling time $=43 \mathrm{~ms}$ (i.e. one measurement every $43 \mathrm{~ms}$ ) } & \\
\hline & \multicolumn{2}{|l|}{ Total measurements $=50,000$} & \\
\hline & \multicolumn{2}{|c|}{ Total test duration $=36 \mathrm{~min}(\sim 2867$ cycles $)$} & \\
\hline
\end{tabular}

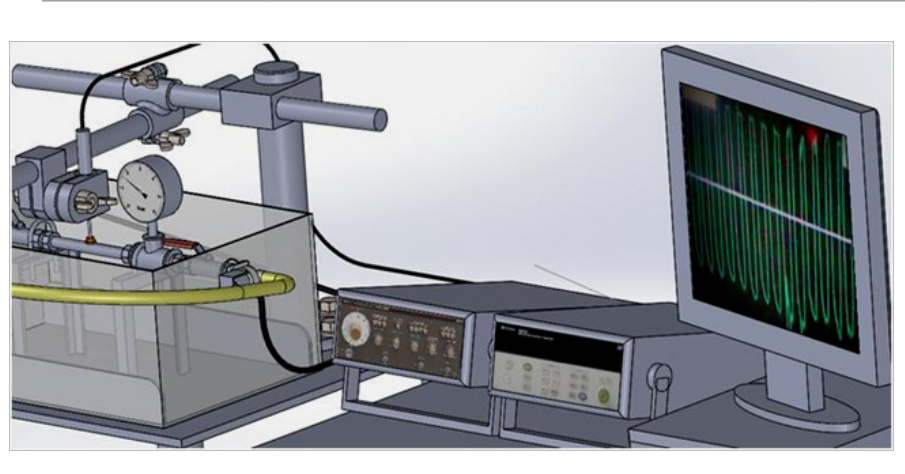

Figure 4 Schematic of the prosthetic wall distention measuring chain.

I: Linear Variable Differential Transformer (LVDT) sensor: maximum course $=1 \mathrm{Imm}$; resolution $=0.1 \mu \mathrm{m}, 2$ : Sensor feeler, 3: Prosthesis specimen before being stretched, 4: Computer screen, 5: Power supply unit, 6: Data logger switch unit (Agilent 34970A)

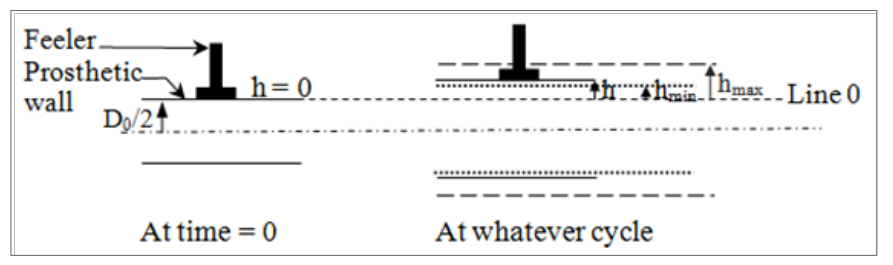

Figure 5 Specification of the sensor feeler heights $\left(h, h_{\min }\right.$ and $\left.h_{\max }\right)$ during the prosthetic tube cyclic distentions.

\section{Results and discussion}

A quasi-stabilization of the dilation tendency was noticed for the different woven tube specimens after 5000 circumferential tensile cycles. The Figure 6 showing a typical elongation versus time curve for a cyclic circumferential tensile test applied to vascular graft clearly illustrates the fatigue inflicted over time and which results in a remnant dilation of the textile structure.

The dilation percentage at a cycle $i$, denoted Dilat $_{\%(i)}$ can be defined as:

$$
\text { Dilat }_{\%(\mathrm{i})}=100 \times \frac{\mathrm{p}_{\mathrm{i}}-\mathrm{p}_{0}}{\mathrm{p}_{0}}
$$

Where $p_{0}$ is the original perimeter of the prosthetic tube (measured at time $=0$ ) and $p_{i}$ its perimeter at cycle $i$.

Noting $e_{0}$ the original spacing (at time $=0$ ) of the hemi cylindrical rods (due to the application of pretension), $\varnothing$ their diameter and $E_{i}$ the specimen elongation recorded at cycle i (Figure 7), the dilation percentage Dilat $_{\%(i)}$ is calculated according to the following equation:

$$
\text { Dilat }_{\%(\mathrm{i})}=100 \times \frac{2 \mathrm{E}_{\mathrm{i}}}{\partial \phi+2 \mathrm{e}_{0}}
$$

The overall increase of dilation between the first and the last cycle can then be written:

$$
\text { Dilat }_{\%}=\text { Dilat }_{\%(5000)}-\text { Dilat }_{\%(1)}=100 \times \frac{2\left(\mathrm{E}_{5000}-\mathrm{E}_{1}\right)}{\partial \phi+2 \mathrm{e}_{0}}
$$

Since artificial arterial substitutes should present mechanical behaviors as close as possible to those of the natural arteries they are supposed to replace, the interest that the textile structure is compliant should be emphasized. ${ }^{10,30}$ Arterial substitutes have to present sufficient circumferential extension under overpressure effect (Eq. 2). ${ }^{40}$

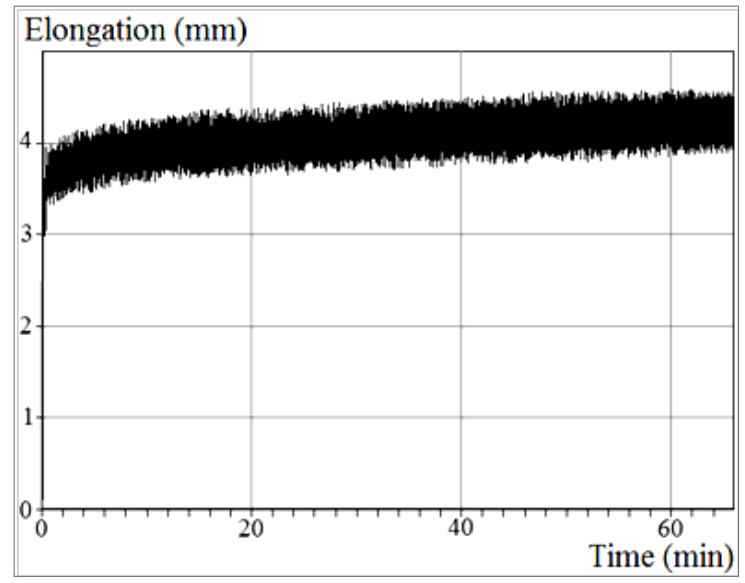

Figure 6 Curve obtained for cyclic circumferential tensile test applied to a $\mathrm{Cl}$ tube specimen. 


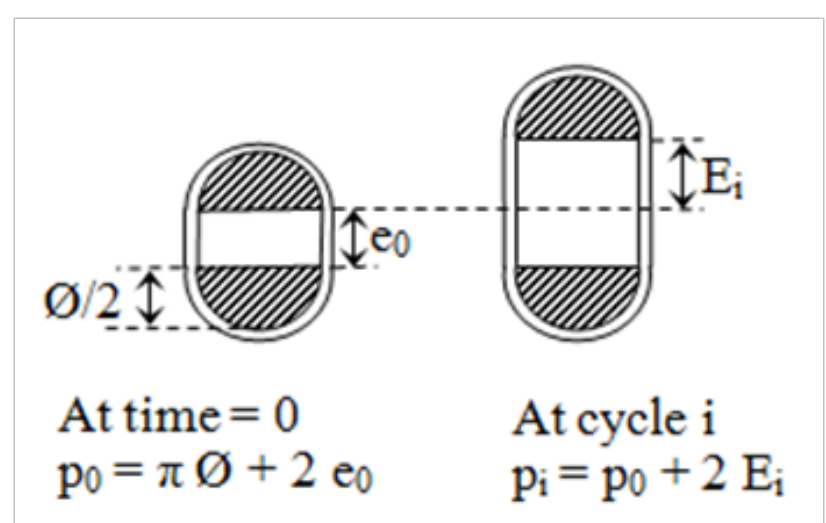

Figure 7 Dilation of prosthetic tube specimens during cyclic circumferential tensile test (cross-sectional view).

By examining the results obtained from calculation of dilation percentages according to Eq. 4-5 (Table 4), it can be noticed that $\mathrm{C} 1$ contexture has the greatest immediate compliance $\left(0.8510^{-2}\right.$ with more than $10 \%$ dilation at the first tensile cycle. This is due to the use of a textured weft yarn characterized by a bulky and undulating structure thus conferring a great aptitude for extension on the yarn and then on the fabric. Texturing, generally accomplished by thermomechanical post spinning treatments (achieved by simultaneous action of tension, twist and temperature), improves endothelial recolonization of the prosthesis in vivo. ${ }^{19,41}$

Table 4 Dilation percentages after cyclic circumferential tensile tests

\begin{tabular}{lllll}
\hline Fabric contexture & & Cl & C2 & C3 \\
\hline \multirow{2}{*}{ Dilat\% (I) } & Mean & 10.16 & 5.78 & 9.44 \\
& CV (\%) & 7.4 & 8.2 & 6.3 \\
Dilat\% (5000) & Mean & 14.35 & 10.33 & 15.92 \\
Dilat\% & CV (\%) & 7.9 & 9.1 & 6.5 \\
Compliancea (\% dilation per 100mmHg) & 0.85 & 0.48 & 0.79 \\
\hline
\end{tabular}

ainitial compliance measured at first cycle between 0 and $1200 \mathrm{mmHg}$.

Although having exactly the same warp and weft counts as well as similar yarn fineness and area densities, the $\mathrm{C} 2$ and $\mathrm{C} 3$ prosthetic fabrics dilated differently during cyclic tests (Table 4). The twisted structure of Viscosuisse yarns gave the $\mathrm{C} 3$ fabric a greater potential for transversal extensibility at first tensile cycle than intermingled configuration of Diolen weft yarns used for $\mathrm{C} 2$ fabric. Nevertheless, when dilation became permanent and caused the textile structure to lose extensibility at the end of fatigue cycles, C2 contexture (Dilat $=4.55)$ has been more stable than $\mathrm{C} 3$ one $\left(\right.$ Dilat $\left._{\%}=6.48\right)$ because of the greater microstructural stability of Diolen yarns acquired during prosthetic crimping thermal treatments and proved in previous works. ${ }^{18}$ However, the best (smallest) overall increase of dilation was recorded for the $\mathrm{C} 1$ contexture woven with Dacron yarns which are approved by the FDA for medical applications.

According to the characterization of commercial vascular prostheses carried out by Guidoin et al. ${ }^{19}$ the dilation of woven prostheses varies between 0.2 and $2 \%$ and that of warp knitted prostheses varies between 1.6 and $8 \%$ under $120 \mathrm{mmHg}$ pressure. For mechanical constraints equivalent to those applied in our dynamometer tests $(\sim 1200 \mathrm{mmHg})$, the literature ${ }^{30,42}$ evokes a circumferential elongation varying between 80 and $100 \%$ for arterial tissues, and an average of about $7 \%$ for PET woven commercial prostheses and $10 \%$ for those knitted. The dilation capacity of the tested materials, in particular the $\mathrm{C} 1$ and $\mathrm{C} 3$ tubes, seems to present interesting performances compared with commercially available prostheses, although these performances could be altered by subsequent finishing treatments, especially sterilization (generally achieved by alkylating gas treatment, $\gamma$ radiation or plasma technologies).

Compared to unidirectional tensile tests carried out on mechanical testing machine, multidirectional stresses applied by compressed water on the developed hydrodynamic test bench allow better in vitro simulation of the complex mechanical constraints to which the prosthetic walls are subjected under physiological conditions.

To check the impact of the rubber tube used to seal textile fabrics on the results provided by the test bench, experiments without prosthetic specimens were first performed in accordance with the operating conditions of Table 3. No significant difference in dilation has been detected along the pulsatile cycles. This confirms that the rubber tubes used thus retained their elasticity throughout the fatigue tests for the pressure range used.

The Figure 8 shows the typical evolution of the height $h$, which corresponds to the relative position of the prosthetic wall upper boundary compared to its initial position (at time $=0$ ), on six selected scan series. A change in wall expansion at both $\mathrm{h}_{\max }$ (for $2.7 \mathrm{bar}$ ) and $\mathrm{h}_{\min }$ (for 1.8 bar) was clearly noted. The fatigue cycles seem to have generated significant variations in the distensibility of the prosthetic tube as well as its expansion amplitude.

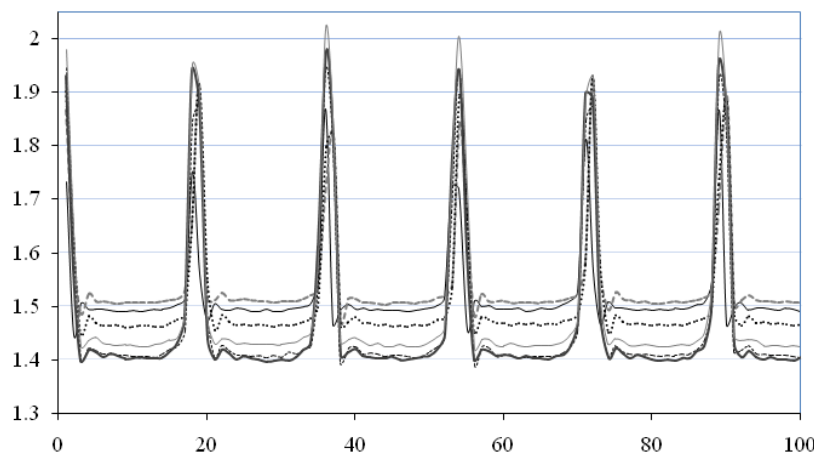

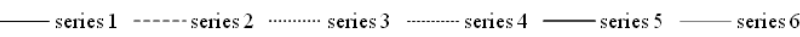

Figure 8 Cyclic distention curves of a $\mathrm{Cl}$ prosthetic wall specimen represented for six series of 100 scans each, covering the entire measurement range.

Series I: 12-1II, Series 2: 10007-10106, Series 3: 20006-20105, Series 4: 3000I-30100, Series 5: 39998-40097, Series 6: 49890-49989.

To better understand this evolution, it was proposed to share the 50,000scans, obtained for each hydrodynamic test, in 500series each comprising 100 measurements (every series then corresponds to 5.7 cycles and lasts $4.3 \mathrm{~s}$ ) and calculate the local minimum and maximum values of feeler height for each scan series. The 500 average values of $h_{\min }$ and $h_{\max }$ for each prosthetic contexture were then shown in Figure 9. 
The Figure 9 shows the two "asymptote lines" that delimit the expansion area for each type of contexture. As the test progresses, the textile prosthetic structure lose its elasticity under the fatigue effect and the two lines tend to deviate: systolic dilation increases and diastolic dilation decreases accordingly. Indeed, because for a continuous and sustained pulsatile rhythm, the fluid volume led by the prosthetic tube is shared between the systolic and diastolic phases, when a systolic over dilation (increase of systolic volume) occurs from one cycle to another, it induces a decrease in the diastolic volume and subsequently less dilation of the prosthetic wall during this phase $\left(\mathrm{h}_{\min }\right.$ decreases).

By relying on the Eq. 2 to calculate the dynamic compliance of prosthetic structures, the latter is written:

$$
\mathrm{C}=\frac{\left(\mathrm{h}_{\text {max }}-\mathrm{h}_{\text {min }}\right)}{\Delta \mathrm{P}\left(\mathrm{h}_{\text {min }}+\mathrm{D}_{0} / 2\right)}
$$

With: $D_{0}=18 \mathrm{~mm}$ (Table 1) and $\Delta P=675 \mathrm{mmHg}$ (Table 3).

According to Figure 10, the studied structures showed different

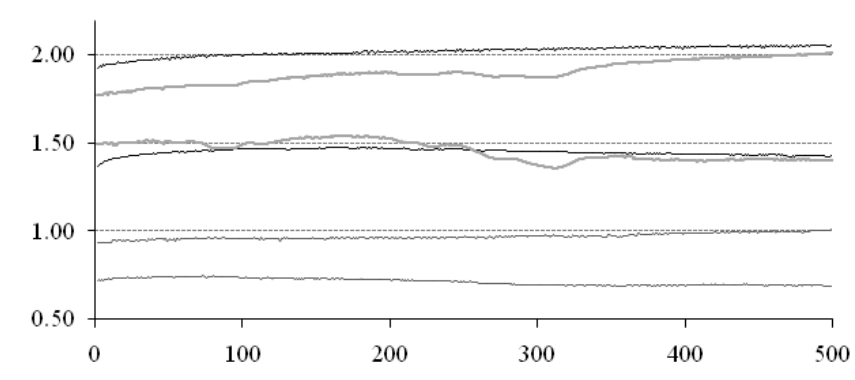

$-\mathrm{h} \min$ and $\mathrm{h} \max (\mathrm{C} 1)-\mathrm{h} \min$ and $\mathrm{h} \max (\mathrm{C} 2)-\mathrm{h} \min$ and $\mathrm{h} \max (\mathrm{C} 3)$

Figure 9 Evolution of prosthetic distention (local minima and maxima) at cyclic pressures as a function of time for $\mathrm{Cl}, \mathrm{C} 2$ and $\mathrm{C} 3$ contextures.

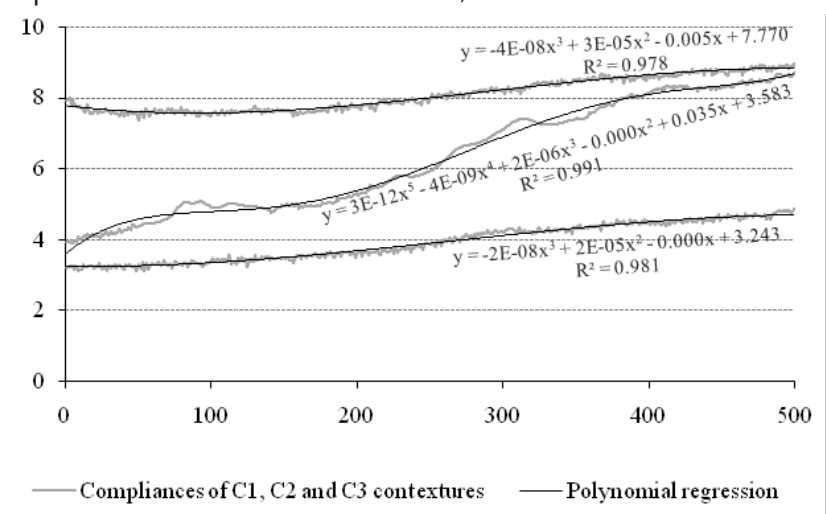

Figure 10 Dynamic compliance curves for $\mathrm{Cl}, \mathrm{C} 2$ and $\mathrm{C} 3$ prosthetic contextures tested in the 1.8-2.7bar pressure range.

\section{Conclusion}

The aim of this study was to evaluate the mechanical behavior of prosthetic tubes subjected to fatigue stresses under realistic test conditions performed in vitro. For this purpose, three tubular fabric contextures have been woven with various polyester multifilament yarns (Dacron, Diolen and Viscosuisse) and thermally crimped to levels of compliance during the hydrodynamic test due essentially to the various yarn structures involved as well as their different macromolecular configurations acquired during the thermal treatments of prosthetic crimping. ${ }^{18,43}$ As already explained, the fatigue inflicted on the textile prosthetic structures was responsible for the increase of their extensibility and consequently of their compliance. Both starting from similar initial compliances $\left(3.3-3.810^{-5} \mathrm{mmHg}^{-1}\right)$, the $\mathrm{C} 2$ contexture stabilized at the last cycle at compliance close to $4.810^{-5} \mathrm{mmHg}^{-1}$, while that of $\mathrm{C} 3$ has risen to $8.810^{-5} \mathrm{mmHg}^{-1}$ $(+130 \%)$ which could seriously disturb the conditions of blood flow in vivo. ${ }^{44,45}$ However, the circumferential structure woven with a textured weft yarn used for the $\mathrm{C} 1$ contexture assured it a good initial compliance $\left(7.610^{-5} \mathrm{mmHg}^{-1}\right)$ which remains relatively stable and amounted to only $8.810^{-5} \mathrm{mmHg}^{-1}(+16 \%)$ at the end of fatigue cycles.

According to Salacinski et al. ${ }^{46}$ the medium and large diameter arteries expand up to $5 \%$ under a pressure of $120 \mathrm{mmHg}$, which corresponds to a compliance of $12510^{-5} \mathrm{mmHg}^{-1}$. In addition, according to Ballyk et al. ${ }^{11}$ the average compliance of a healthy artery is about $6010^{-5} \mathrm{mmHg}^{-1}$, while it does not exceed $2010^{-5} \mathrm{mmHg}^{-1}$ for woven and knitted vascular prostheses. ${ }^{23}$

achieve an accordion pleat wall configuration necessary to improve the longitudinal flexibility of the graft as well as its resistance to both radial compression and kinking.

Preliminary cyclic circumferential tensile tests have been applied by using mechanical testing machine imposing two limit forces on woven prosthetic tubes. Specimens made with Dacron (textured) and Viscosuisse (twisted) weft yarns recorded interesting initial compliances $(0.85$ and $0.79 \%$ dilation per $100 \mathrm{mmHg}$, respectively) while those using Diolen (intermingled) weft yarns appeared less extensible with $5.78 \%$ dilation at first cycle and only $10.33 \%$ at last cycle.

For a better simulation of the effect of mechanical aging induced on the prosthetic wall, a new test bench has been developed. It allows the injection of pulsatile water adjustable in frequency and pressure in vascular grafts previously sealed by a rubber bladder while simultaneously monitoring the prosthesis wall distention by a high resolution displacement transducer linked to data acquisition software. The latter stores up to 50,000 measurements (or scans) with an adjustable measuring frequency.

Curves showing the dynamic compliances for the different contextures have been therefore elaborated. They illustrate the ability of prosthetic tubes to dilate throughout fatigue cycles in the chosen pressure range: $1350-2020 \mathrm{mmHg}$ (stresses are thereby 17 times greater than the physiological ones). Owing to their thermally stabilized macromolecular structures, ${ }^{18}$ fabrics made with Diolen and Dacron weft yarns showed relatively stable compliances under super physiological stresses imposed on them throughout the fatigue test, although the second prosthetic structure was twice as compliant as the first. This is due to the use of textured yarns whose corrugation offers great potential for extensibility. ${ }^{5,19}$ Furthermore, the compliance curves also revealed a too great tendency to increase (which could induce serious blood flow disturbances) during the fatigue cycles for the contexture made with Viscosuisse weft yarns. However, this tendency was less obvious in the preliminary dynamometer tests.

Changes in wall compliance have a great impact on the mechanical behavior of implants and affect the graft patency in the human body. 
Therefore, compliance must be rigorously evaluated and optimized during all stages of manufacture and finishing including repeated sterilizations that could alter the textile prosthetic structure. While several outstanding research projects aim to perfect the techniques for measuring in vitro compliance, a true in vivo compliance determination is unfortunately not yet available.

\section{Acknowledgements}

None.

\section{Conflict of interest}

Author declares there is no conflict of interest in publishing the article.

\section{References}

1. Dieval F, Mathieu D, Durand B. Influence of textile structure on longitudinal ruptures' localization of the vascular prostheses. Text Res $J$. 2008; 78(5): 427-438

2. Damme HV, Deprez M, Creemers E, et al. Intrinsic structural failure of polyester (dacron) vascular grafts. A general review. Acta Chir Belg. 2005;105(3):249-255.

3. Riepe G, Loos J, Imig H, et al. Long-term in vivo alterations of polyester vascular grafts in humans. Eur J Vasc Endovasc Surg. 1997;13(6):540-8.

4. Nunn DB, Carter MM, Donohue MT, et al. Postoperative dilation of knitted Dacron aortic bifurcation graft. J Vasc Surg. 1990;12(3):291-7.

5. Pourdeyhimi B. Vascular grafts: textile structures and their performance. Text Prog. 1986;15(3):1-30.

6. Schroeder TV, Eldrup N, Just S, et al. Dilatation of aortic grafts over time: What to expect and when to be concerned. Semin Vasc Surg. 2009;22(2):119-24

7. Goëau-Brissonniere OA, Qanadli SD, Ippoliti A, et al. Can knitting structure affect dilation of polyester bifurcated prostheses? A randomized study with the use of helical computed tomography scanning. J Vasc Surg. 2000;31(1):157-8.

8. Mattens E, Engels P, Hamerlijnck R, et al. Gelseal $₫$ versus Gelweave ${ }^{\circledR}$ dacron prosthetic grafts in the descending thoracic aorta: a twoyear computed tomography scan follow-up study. Cardiovasc Surg. $1999 ; 7(4): 432-5$.

9. Igari T, Iwaya F, Hoshino S. Postoperative alteration in the size of dacron vascular prostheses implanted in the infrarenal abdominal aorta. Surg Today. 1995;25(7):605-7.

10. Ulcay Y, Pourdeyhimi B. Effect of dilation on the mechanical characterization of vascular prostheses. Fibers \& Polymers. 2005;6(1):49-54

11. Ballyk PD, Walsh C, Butany J, et al. Compliance mismatch may promote graft-artery intimal hyperplasia by altering suture-line stresses. $J$ Biomech. 1997;31(3):229-37.

12. Berman SS, Hunter GC, Smyth SH, et al. Application of computed tomography for surveillance of aortic grafts. Surg. 1995;118(1):8-15.

13. Robinson D, Lennox A, Englund R, et al. Graft dilatation following abdominal aortic aneurysm resection and grafting. Aust $N Z J$. Surg. 1999;69(12):849-51.

14. Quarmby J, Burnand K, Lockhart S, et al. Prospective randomized tria of woven versus collagen-impregnated knitted prosthetic Dacron grafts in aortoiliac surgery. Br J Surg. 1998;85(6):775-7.
15. Alimi Y, Juhan C, Morati N, et al. Dilation of Woven and Knitted Aortic Prosthetic Grafts: CT Scan Evaluation. Ann Vasc Surg. 1994;8(3):238-42.

16. Sporn E, Kubin K, Hoblaj T, et al. Dacron grafts dilate more than Stretch PTFE grafts after abdominal aortic aneurysm repair - long-term results of a prospective randomized trial. Eur Surg. 2008;40(2):66-71.

17. Mikati A, Marache P, Watel A, et al. End-to-side Aortoprosthetic Anastomoses: Long-term Computed Tomography Assessment. Ann Vasc Surg. 1990;4(6):584-91.

18. Khlif H, Dhouib S, Ben Abdessalem S, et al. The impacts of therma treatments on the physical properties of textile vascular prostheses. Fibers \& Polymers. 2012;13(1):68-78.

19. Guidoin R, King M, Deng X, et al. Arterial Replacement: Principles and Applications. $1^{\text {st }}$ ed. Kieffer E, editor. Paris: AERCV; 1992.

20. Feldstein M \& Pourdeyhimi B. A study of the influence of manufacturing techniques on the mechanical properties of Dacron fibres employed in vascular grafts. J Mater Sci Lett. 1990;9(9):1061-5.

21. Dieval F, Khoffi F, Mir R, et al. Long-Term Biostability of Pet Vascular Prostheses. Int J Polym Sci. 2012:1.

22. Ben Abdessalem S, Mokhtar S. A new concept of three dimensional weaving of bifurcated vascular prostheses. Indian J Fibre Text Res. 2006;31(4):573-6.

23. Mokhtar S, Ben Abdessalem S, Sakli F. Optimization of textile parameters of plain woven vascular prostheses. J Text I. 2010;101(12):1095-1105.

24. Khlif H, Ben Abdessalem S, Dhouib S, et al. Contribution to the improvement of textile vascular prostheses crimping. Trends $\mathrm{Appl} \mathrm{Sci}$ Res. 2011;6(9):1019-27.

25. Le Magnen JF, Mathieu D, Chakfe N, et al. Critical approach to standardized tests. Paper presented at the $1^{\text {st }}$ European Symposium of Vascular Biomaterials ESVB2001; 2001

26. Dieval F, Chakfe N, Bizonne SC, et al. Mechanical tests for evaluating vascular prostheses. ITBM-RBM. 2001;22(2):70-87.

27. Khlif $\mathrm{H}$, Ben Abdessalem S. Influence of Crimping Process Parameters on Vascular Prostheses Mechanical Performances. RJTA. 2011;15(3):28-37.

28. Chung S, Ingle NP, Montero GA, et al. Bioresorbable elastomeric vascular tissue engineering scaffolds via melt spinning and electrospinning. Acta Biomater. 2010;6(6):1958-67.

29. Pourdeyhimi B, Wagner D. On the correlation between the failure of vascular grafts and their structural and material properties: a critical analysis. J Biomed Mater Res A. 1986;20(3):375-409.

30. Singh C, Wong CS, Wang X. Medical Textiles as Vascular Implants and Their Success to Mimic Natural Arteries. J Funct Biomater 2015;6(3):500-25.

31. Tu R, Mcintyre J, Hata C, et al. Dynamic internal compliance of a vascular prosthesis. ASAIO Trans. 1991;37(3):M470-2.

32. International standard. Cardiovascular implants - Tubular vascular prostheses - Circumferential tensile strength. ISO/DIS ; 1998.

33. International standard. Cardiovascular implants - Tubular vascular prostheses - Usable length. ISO/DIS; 1998

34. Jay J, Boissier C, Fouquet R, et al. ITBM-RBM. 1996;17:273.

35. Flaud P, Geiger D, Oddou C, et al. Experimental device for modeling blood flow in the arteries. Rev Phys Appl. 1975;10(2):61-7.

36. Klip W. Velocity and damping of the pulse wave. Hague: University of Michigan; 1962. 105 p. 
37. Armentano RL, Jasso DV, Cymberknop LJ, et al. Proceedings, 37 Annual International Conference of the IEEE Engineering in Medicine and Biology Society EMBC. Italy: IEEE; 2015.

38. Maâtoug N, Sahnoun M, Sakli F. Tunisian Patent. 2009.

39. Maâtoug N, Sahnoun M, Sakli F. Statistical Analysis of Surface Roughness Parameters for Weft Knitted Fabrics Measured by the Textile Surface Tester (TST). J Eng Fibe Fabr. 2012;7(4):104-112.

40. Gholipour B. What is a normal heart rate? American Heart Association. 2018.

41. Pourdeyhimi B, Text C. A review of structural and material properties of vascular grafts. J Biomater Appl. 1987;2(2):163-204.
42. Pietrabissa R. Biomaterials for prostheses and artificial organs. Patron, editor. Bologna; Biomedical engineering; 1996. 307 p.

43. Azaiez M, Zbali I, Ben Abdessalem S. Iranica J Energy \& Environ. 2011;4:331.

44. Ben Abdessalem S, Durand B, Akesbi S, et al. Blood flow in a polyester textile vascular prosthesis: experimental and numerical study. Text Res $J$. 2001;71:178-83.

45. Ben Abdessalem S, Durand B, Akesbi S, et al. Numerical simulation of blood flow in a curved textile vascular prosthesis. $J$ Text I. 2005;96(2):117-22.

46. Salacinski HJ, Goldner S, Giudiceandrea A, et al. The mechanical behavior of vascular grafts: a review. J Biomater Appl. 2001;15(3):241-78. 